\title{
Third BACG Photochemical Processing Workshop Held in Edinburgh
}

The Third Photochemical Processing Workshop was held by the British Association for Crystal Growth (BACG) in association with the Institute of Physics, the Royal Society of Chemistry, and the Institute of Electrical Engineers at Heriot-Watt University, Edinburgh, Scotland, March 25, 1988. Significant developments in the field of photochemical processing were aired at this year's workshop. Although there was a strong bias towards the light-assisted growth, etching and processing of semiconductors, the proceedings included valuable contributions on polymer ablation, metal and dielectric deposition, and the use of lasers to produce superconducting films.

One of the largest topics for discussion was the photoetching of semiconducting materials. Pulsed excimer sources have been used to etch $\mathrm{GaAs}$ directly by Gillian Davis (Rutherford Appleton Laboratory). This method can be used to produce either smooth surfaces or, by using interference, gratings with a periodicity of $1.5 \mu \mathrm{m}$. The process works well in a nitrogen atmosphere but is faster in the presence of oxygen. Don Rodway of the Royal Signals and Radar Establishment (RSRE) has used similar but less aggressive conditions to remove carbon contamination from GaAs substrates prior to MBE growth. Clearly the compatibility of photochemical etching and cleaning methods with, for example, MOVPE growth makes this technology an attractive choice for in situ processing.

The use of iodine-substituted methanes in etching III-V semiconductors has stimulated interest at both British Telecom Research Laboratory (BTRL) and University of Manchester Institute of Science and Technology (UMIST). Ken Durose (BTRL) has demonstrated the use of $\mathrm{CH}_{3} \mathrm{I}$ to produce directly written etched lines in InP. Coatings of native oxide were used to change the steepness of the walls and definition of the grooves as required. Peter Goulding presented work on a similar system, $\mathrm{CH}_{2} \mathrm{I}_{2}$ on $\mathrm{GaAs}$ which was carried out in Martyn Pemble's laboratory at UMIST. Apparatus which facilitates the transfer of substrates from a processing environment directly into a UHV analytical chamber enabled details of the adsorption of the reactive etching species to be investigated. Recent work on laser photoablation of spin-on glass and the novel polyethylcyanoacrylate photo-resist was discussed by Hogan et al. (Trinity College Dublin, and Loctite (Ireland). Affrossman et al. (Strathclyde University) reported new observations concerning argon-laserinduced etching of silicon.
Laser-induced deposition and growth also attracted a sizeable number of papers. Haq, Dobson, and Irvine (Birmingham University and RSRE) presented recent results on the nucleation of cadmium layers on semiconductors, while a paper by Daniel and May of GEC (General Electric Company, U.K.) discussed ArF laser deposition of large-area high quality tungsten films. Silicon oxide deposition by hard UV radiation from a deuterium lamp was reported by Bhatnagar and Milne (Cambridge University), and included a novel method of minimizing the usual window clouding problem. Boyd and Nayar (University College London) and Goodall and Arthur (Rutherford Appleton Laboratory) showed results of the first oxide layers to be directly grown in a patterned fashion on a silicon surface, using a selective mask imaging technique called direct growth lithography. The Heriot-Watt group of Milne, Black, Wilson, and John described the morphology and electrical characteristics of rectifying silicon pn junctions produced by pyrolytic laser chemical vapor deposition.

Area selective photoepitaxy was the subject of two papers, significant results being presented by Steve Rolt of STC (Standard Telephones \& Cables) on GaAs and by Stuart Irvine (RSRE) on CdTe. Both have achieved good spatial confinement which has been shown to be purely photolytic rather than pyrolytic. The RSRE work highlighted the importance of using appropriate precursors; for CdTe growth diethyl telluride gives noticeably better spatial confinement than dimethyl ditelluride. Further developments of these and other photoepitaxial processes will undoubtedly be of great technological interest and we can no doubt look forward to news of continuing progress in the field.

The conference was delighted to welcome T.S. Baller and G.N.A. van Veen from Philips at Eindhoven. Particular interest was shown in their presentation on the use of excimer lasers to produce superconducting films. Explosive photoablation was used to prepare stoichiometric films of $\mathrm{YBa}_{2} \mathrm{Cu}_{3} \mathrm{O}_{78}$ (123) on $\mathrm{SrTiO}_{3}$ substrates. $\mathrm{Ab}$ lation could well become increasingly important in the handling of superconducting and other difficult materials.

Once more the meeting achieved its aim of being a forum for lively discussion and the presentation of up-to-date work. The vast potential of photochemical processing was highlighted, as was the rapid progress being made toward the use of photochemistry in a wide range of important applications.

Next year's meeting, around March/ April 1989, will be hosted by Ian W. Boyd in the Department of Electronic and Electrical Engineering at University College London.

Ken Durose British Telecom Research Laboratory

\section{Scientific Basis for Nuclear Waste Management}

\author{
October 10-13, 1988 \\ Internationales Congress Centrum \\ Berlin, W. Germany
}

\begin{abstract}
Co-sponsored by MRS, the Hahn-Meitner-Institut and other institutions, the 12th International Symposium on the Scientific Basis for Nuclear Waste Management will focus on the science underlying waste forms (vitreous, ceramic, spent fuel, cement), waste isolation (container materials, backfill, repository), and modeling and performance assessment.
\end{abstract}

Contact: Ms. Helga Fuchs, Hahn-Meitner Institut, Berlin GmbH, Glienicker Strasse 100, D-1000 Berlin 39, W. Germany; telephone (49) 30 8009-2291; fax (49) 30 8009-2999, or telex 185763. 